Sergio Elias Vieira Cury ${ }^{1 *}$ Brunno Santos de Freitas Silva ${ }^{2}$

André Caroli Rocha ${ }^{3}$ Celso Augusto Lemos-Junior

Décio dos Santos Pinto Junior ${ }^{4}$

${ }^{1}$ UniFOA.

2 UniEvangélica.

${ }^{3}$ Hospital das Clínicas FMUSP

${ }^{4}$ Faculdade de Odontologia da Universidade de São Paulo.

Correspondence to:

Faculdade de Odontologia - Universidade de São Paulo

Av. Prof. Lineu Prestes 2227 São Paulo SP 05508-900 Brazil.

E-mail: sergiocury@usp.br

Article received on September 19, 2012. Article accepted on August 6, 2013.

DOI: $10.5935 / 2525-5711.20160019$

\section{Osteoid osteoma of the mandible: case report}

\section{Abstract:}

We present a rare case of a 39-year-old woman who had a painless mass in the mandibular symphysis. Histological findings showed a benign osteoid osteoma.

Keywords: Osteoblastoma; Osteoma, Osteoid; Mandibular Diseases; Diagnosis, Differential 


\section{INTRODUCTION}

Osteoid osteoma (OO) is a solitary benign tumour ${ }^{2}$. The femur, tibia, and vertebrae are most often involved; OO rarely affects the jaws. It most often occurs as an intracortical lesion, although it may also involve periosteal and medullary portions of bone $\mathrm{e}^{4}$. OO affects younger people, mostly in the second and third decades, and commonly is found more frequently in males compared to females, at a ratio of 3 to $1^{4,7}$. The radiographic aspect consists of a lytic, small and round area in the subjacent cortical bone surrounded by sclerotic bone ${ }^{6}$. OO has a limited growth potential and the nidus usually measures no more than 1.0 to $1.5 \mathrm{~cm}$ in its maximum dimensions ${ }^{1}$. The histological features are the same as those of osteoblastoma $(\mathrm{OB})$ and thus these two lesions are easily confused ${ }^{3}$.

\section{CASE REPORT}

A 39-year-old woman was referred to the Stomatology Clinic of the Dental School at University of Sao Paulo, Brazil, in January 2006, with the complaint of a painful swelling in the anterior mandible with 4-month duration. On physical examination, a bone expansion with petrous consistency was noted on the mandibular symphysis (Figure 1A). Radiographs revealed a mixed radiolucent/radiopaque lesion with approximately $1.0 \mathrm{~cm}$ in diameter. An additional occlusal radiograph showed a sclerotic cortical nodule (Figure 1B). The patient was admitted for surgical management under local anesthesia and the lesion was removed by an intraoral approach. These consist of bone segment resection with nidus removal and local curettage (Figure $1 \mathrm{C}$ and $\mathrm{D})$. The specimen consisted of a hard, welldemarcated nodule with about $1.0 \mathrm{~cm}$ in diameter.

Microscopically, the lesion exhibited a round calcified mass well demarcated from the adjacent bone. Proliferation of mature medullary bone with fused trabeculae, prominent osteoblasts and osteoclasts was seen. A fibrous stromal tissue rich in fusiform cells was observed close to the ossification plates, which presented a mosaic pattern. In the center of the lesion, the bone tissue was separated from the surrounding sclerotic lamellar bone by connective tissue and dilated capillaries (Figure $1 \mathrm{E}$ and $\mathrm{F}$ ).

After 10 months follow-up no recurrence was observed.

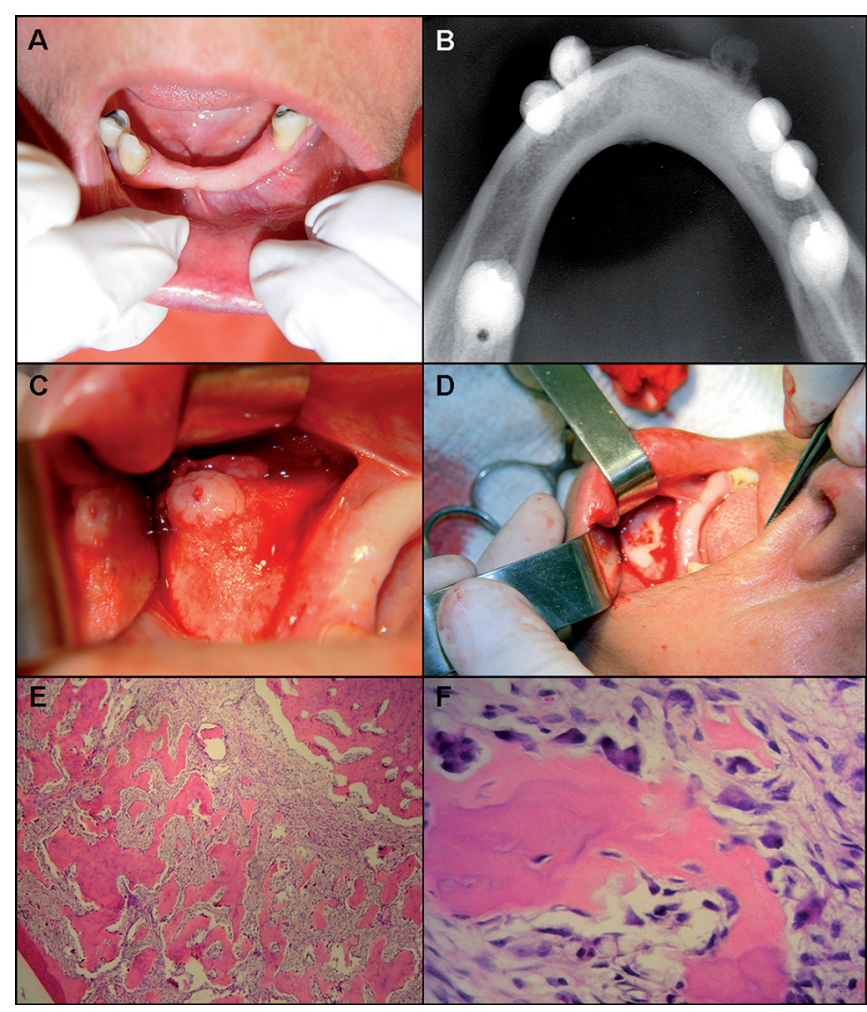

Figure 1. Bone expansion on the mandibular symphysis (A). Occlusal radiograph showing a sclerotic cortical nodule (B). Surgical removal of a hard and well-demarcated nodule (C and D). Proliferation of mature medullary bone with fused trabeculae within a fibrous stromal tissue rich in fusiform cells was observed close to the ossification plates, which presented a mosaic pattern - low magnification (E). In detail, prominent osteoblasts and osteoclasts are seen - high magnification (F).

\section{DISCUSSION}

OO is very rare lesion in the jaws. Many cases involving long bones have been described in the literature, yet only twelve cases were reported on the jaws in the English literature ${ }^{4,6,7}$. A study conduced by Lichtenstein in $1965^{5}$ described the differences between $\mathrm{OO}$ and benign $\mathrm{OB}$. The cases of $\mathrm{OO}$ and benign $\mathrm{OB}$ reported as arising in the jaws are often histologically similar, and the clinical pictures frequently overlap ${ }^{1}$. OO arises from the cortical bone, and $\mathrm{OB}$ arises from the medullary bone. $\mathrm{OB}$ usually affects younger patients than $\mathrm{OO}$, and $\mathrm{OO}$ is more painful than OB. Differentiation has also been made on the basis of size and symptoms. OO is usually less than $1 \mathrm{~cm}$ in diameter, and $\mathrm{OB}$ is usually larger than $2 \mathrm{~cm}$. A very characteristic symptom of osteoid osteoma is spontaneous severe pain, whereas OB is frequently painless ${ }^{7}$. 
These latter tumors share a similar histomorphology consisting of a growth center (nidus), whose features are well-described. Some osteoblastomas contain large cells with an abundant and dense eosinophilic cytoplasm and large eccentric vesicular nuclei with prominent nucleoli, so-called "epithelioid osteoblasts", which line the trabeculae and reside within the intertrabecular stroma. The treatment of choice is surgical excision. There have been no reports of recurrences ${ }^{3}$.

\section{REFERENCES}

1. BYERS PD. Solitary benign osteoblastic lesions of bone. Cancer 1986: 22: 43
2. JAFFE HL. Osteoid-osteoma: Benign osteoblastic tumor composed of osteoid and atypical bone. Arch Surg 1935: 31:709.

3. KYRIACOS M. et al. Osteoblastomatosis of bone. A benign multifocal osteoblastic lesion, distinct from osteoid osteoma and osteoblastoma radiologically simulating a vascular tumor: a case report. Skeletal Radiol 2006: Apr 25: [Epub ahead of print] .

4. LEE HE, SHAFI M, HUI JHP. Osteoid osteoma: a current review. J Pediatr Orthop 2006: 26 (5): 695-700.

5. LICHTENSTEIN L. Bone Tumors. 3rd Ed. St Louis, MO, CV Mosby, 1965: 90.

6. LIU CJ, CHANG KW, CHANG KM, CHENG CY. A Variant of Osteoid Osteoma of the Mandible: Report of a Case. J Oral Maxillofac Surg 2002: 60: 219-221.

7. TOCHIRARA S, SATO T, YAMAMOTO H, ASADA K, ISHIBASHI K. Osteoid osteoma in mandibular condyle. Int. J. Oral Maxillofac. Surg 2001: 30: 455-457. 